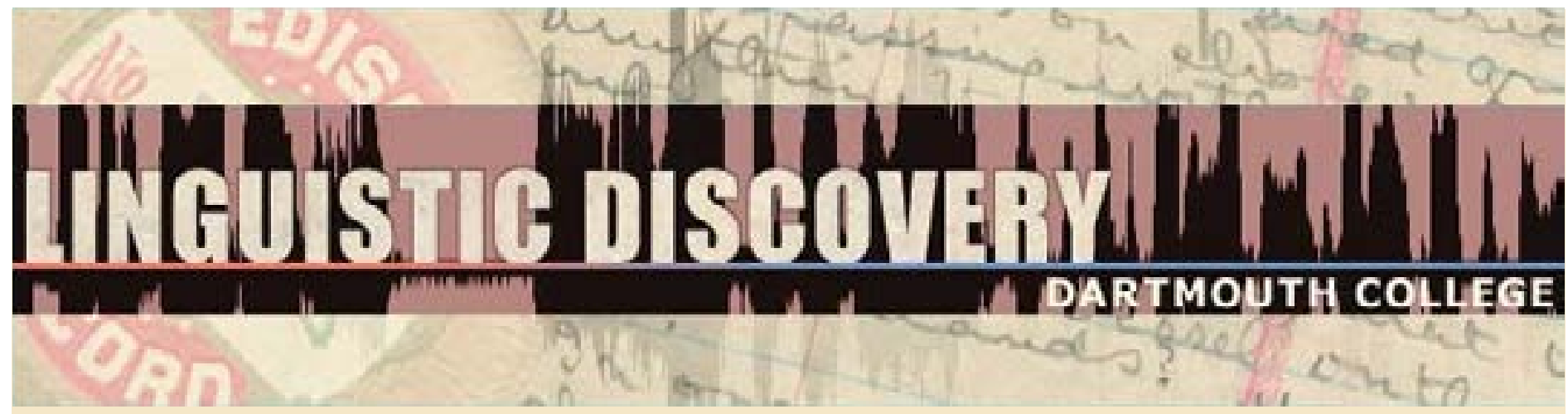

Volume 1

Issue 1 2002
Reanalysis of Passive and Negative Prefixes in Seri

Stephen A. Marlett

SIL International and University of North Dakota

doi: 10.1349/PS1.1537-0852.A.1

url: http://journals.dartmouth.edu/cgi-bin/WebObjects/ Journals.woa/1/xmlpage/1/article/1 


\title{
Reanalysis of Passive and Negative Prefixes in Seri ${ }^{1}$
}

\author{
Stephen A. Marlett \\ SIL International and University of North Dakota
}

Two productive Seri prefixes, negative and passive, are in a limited number of cases reanalyzed as part of the verb stem. This reanalysis has produced homophonous verb forms: one group is clearly analytical (affix + root) and one group is clearly synthetic. The evidence that reanalysis has taken place is presented. These new verb roots enter into new morphological constructions. And since the original analytical verb forms continue to exist, the result is the coexistence of homophonous and sometimes virtually synonymous words (such as the original transitive verb and a new causative verb that is based on a reanalyzed passive).

\section{Introduction}

Certain consonants and vowels which appear at the beginning of verb stems in present-day Seri ${ }^{2}$ are in actuality reanalyzed passive and negative prefixes, prefixes which are still completely productive in the language. So alongside a transitive verb such as $/-Q /$ (where "Q" represents arbitrary phonological material), there may be an intransitive verb / $-\mathrm{pQ} /$ which must be distinguished from the passive form of $/-\mathrm{Q} /$, which is $/-\mathrm{p}-\mathrm{Q} /$. And alongside a verb such as $/-\mathrm{R} /$ (where "R" also represents arbitrary phonological material), there may be a verb $/-\mathrm{mR} /$ which must be distinguished from the negative form of $/-\mathrm{R} /$, which is $/-m-R /$. This is summarized in (1)-(2).
(1) Transitive $/-Q /$
Passive /-p-Q/
(new) Intransitive /-pQ/
(2) Positive /-R/
Negative /-m-R/
(new) Opposite /-mR/

The proposal made here is that reanalysis has taken place by the loss of a boundary, but without the loss of the productivity of the original morphemes or their combinations. This is illustrated with one set of real examples in (3). ${ }^{3}$

\footnotetext{
${ }^{1}$ This article is based on research that has been conducted by the author during the past 25 years, often in collaboration with Mary Moser, and supported by the Summer Institute of Linguistics. I am indebted to several Seri speakers for their judgments on the data, in addition to original sources: María Luis Astorga de Estrella, Oscar Perales, and Xavier Moreno. I also appreciate the very helpful input I received from Cheri Black, Martin Haspelmath, two anonymous reviewers for this journal, and two anonymous reviewers for Diachronica.

${ }^{2}$ Seri is actively spoken by about 700 speakers, virtually all of the ethnic group, in northwestern Mexico. It has been proposed that Seri is an isolate within the (controversial) Hokan stock, and therefore is distantly related (perhaps) to the Yuman languages. In broad typological terms, it is a mildly fusional agglutinative SOV language without case marking. The verb inflects for the person of the subject, direct object, and indirect object, as well as tense/aspect, negation, voice, causative, number, etc., as some of the examples in this paper illustrate.

${ }^{3}$ The data are presented in the practical orthography (generally similar to Spanish) which has been used for more than forty years. The symbols which need special explanation are: $e$ front low vowel, $h$ glottal stop, $l$ voiceless lateral fricative, $j$ voiceless velar fricative, $j \ddot{o}$ voiceless labialized velar fricative, $x$ voiceless uvular fricative, $x \ddot{o}$ voiceless labialized uvular fricative, $z$ voiceless alveopalatal fricative. The capital $C$ which appears in section 4 refers to the empty consonant position discussed in Stemberger and Marlett (1983). For more information on Seri
} 
(3) $\underset{f m\}}{\mathrm{NEG}}+$ fast $\Rightarrow$ slow
Old Lexicon

$m-$ 'Negative'

-iha 'fast'
New Lexicon

$m-$ 'Negative'

-iha 'fast'

-miha 'slow'

This kind of reanalysis, a kind of 'resegmentation', is mentioned in Hoenigswald (1960:40ff), and is claimed by Langacker (1977:64) to be frequent. It fits in with Langacker's claim that one kind of optimality towards which languages tend is "constructional simplicity"; a complex form (affix plus root, i.e. $-m-i h a$ ) is being replaced by a simple form (synchronically simple stem, i.e. $-m i h a$ ). Langacker (1977:58) defines reanalysis as "a change in the structure of an expression or class of expressions that does not involve any immediate or intrinsic modification of its surface manifestation." Such a definition clearly fits this situation.

The matter is less straightforward than one might imagine, however, since the segments in question are not obviously part of the stem. For example, if a verb form with a $p$ after the tense prefix appears in a text, one does not know automatically whether the $p$ is part of the stem or the passive prefix. ${ }^{5}$ But evidence can be presented to show clearly (in many cases) that it is indeed one or the other. These tests are presented in section 2 for the passive prefix and in section 3 for the negative prefix.

The result of this reanalysis of prefix material as stem material is an expansion of the lexicon. For example, alongside the verb -aatj 'pound flat', and its passive forms (with appropriate vowel shortening as part of the passive formation), there is now also the verb -patj 'flattened', from

phonology and morphology, see Marlett (1981) and Marlett (1990), as well as other information available at www.sil.org/mexico/seri/familia-seri.htm.

The following abbreviations are used:

ActNom - Action Nominalizer;

Aug - Augment (primarily used for forming causatives);

Decl - Declarative;

DS - Different Subject (switch reference marker);

Neg - Negative;

$\mathrm{OM}$ - Object Marker (when verb has third person subject and third person direct object);

Psv - Passive;

SubjNom - Subject Nominalizer;

UF - Underlying Form;

UnspSubj - Unspecified Subject;

$1 \mathrm{IO}$ - first person indirect object (ambiguous for number on most verbs);

1Poss - first person Possessor;

2Poss - second person Possessor;

3Poss - third person Possessor;

$1 \mathrm{sDO}$ - first person singular Direct Object;

1 plDO - first person plural Direct Object;

1 sSubj - first person singular Subject;

2sSubj — second person singular Subject;

$1 \mathrm{plSubj}$ - first person plural Subject.

${ }^{4}$ An important distinction between 'reanalysis' and 'grammaticalization' is made by Haspelmath (1992, 1998); his view of the latter also fits this case in Seri: "Grammaticalization is the gradual drift in all parts of the grammar toward tighter structures, toward less freedom in the use of linguistic expression at all levels... constructions become subject to stronger constraints and come to show greater cohesion" (1998: 318).

${ }^{5}$ A Seri hearer of these forms also does not automatically know the answer. As one reviewer has pointed out, the hearer is making abductive inferences (Andersen 1973) which can easily lead to reanalysis of the phonetic facts. 
which has been formed a new causative form -apátj 'flatten' (UF: -aa-patj, -Cause-flattened), which differs semantically from the original verb -aatj in that it is less specific; it neither requires a pounding motion nor a human agent. All three of these verbs are listed in the dictionary which is currently being compiled (Moser et al, in preparation), although productive passive forms are not listed.

\section{(4) Forms listed in dictionary Productive passive forms not listed in dictionary -aatj 'pound flat' $\quad-p$-atj 'pounded flat' (passive) -patj 'flattened' -apátj 'flatten'6}

In section 2 I present a brief overview of regular passive morphology and then show how the etymological passives are distinguished from them. In section 3 I present evidence for the reanalysis of the negative prefix in various verbs. In section 4 I briefly examine possible motivation for the reanalysis. It is seen that, while it is relatively straightforward to provide evidence for the fact that reanalysis has taken place, it is not so easy to understand why it has taken place. $^{7}$

\section{Etymological Passives}

The passive morpheme in Seri has two allomorphs. One appears before vowel-initial roots; it is segmentally $p$ - and causes the ablaut of stems which begin with non-low vowels $(i, i i$ become $e$; $o$, oo become $a$, and for some verbs long low vowels become short). The other allomorph, which usually surfaces as $a h$-, appears before consonants and before prefix vowels (such as in causatives). Passive stems are illustrated in (5).

$\begin{array}{lll}\text { (5) Active stem } & \text { Gloss } & \text { Passive stem } \\ \text {-oocta } & \text { 'look at' } & -p \text {-acta } \\ \text {-iip } & \text { 'carry on head' } & -p-e p \\ -i z i & \text { 'defeat' } & -p-e z i \\ \text {-ap } & \text { 'sew basket' } & -p-a p \\ \text {-aao } & \text { 'pass (place)' } & -p-a a o \\ \text {-aafc } & \text { 'pound' } & -p-a f c \\ \text { - cazni } & \text { 'bite' } & -a h-c a z n i \\ \text {-ahítaj } & \text { 'cause to burn'8 } & -a h-a h i t a j\end{array}$

Compare now the verbs which appear in (6). These are verbs for which I claim that the $p$ and $a h$ which appear in them are historically, but not synchronically, the passive prefix. ${ }^{9}$ I also show, on the right, the verb stem to which they are etymologically related.

\footnotetext{
${ }^{6}$ Such a causative verb would have a passive form: - ahpátj 'pounded flat', a regularly derived form, from underlying -ah-aa-pátj (-Passive-Causative-flattened).

${ }^{7}$ I have not found any evidence that speakers disagree on any of the facts in this paper, although it is unreasonable to expect homogeneity on such matters. The verbs in question were recorded by Edward and Mary Moser sometime in the 1950's or 1960's, and have been checked and re-checked during field work with different speakers up until the present.

${ }^{8}$ This causative verb is derived from the verb -itaj 'burn (intr.). It uses the allomorph - ah of the causative prefix, which is the allomorph typically used for roots which begin with non-low vowels.
} 
(6)

$\begin{array}{ll}\text {-paailx 'go (pl.),10 } & c f . \text {-aailx 'throw (plural object)' } \\ \text {-paaisx 'be clean' } & c f . \text {-aaisx 'clean (something)' } \\ \text {-patj 'flattened' } & c f . \text {-aatj 'pound flat' } \\ \text {-paatjc 'be open' } & c f . \text {-aatjc 'open (something)' } \\ \text {-pacta 'appear, be' } & c f . \text {-oocta 'look at' } \\ \text {-ahcáil 'remain, be lacking' } & c f . \text {-cail 'have extra' } \\ \text {-ahjíit (sg.), -ahjcóil (pl. subj.) 'fall' cf. -jiit (sg.), -jcoil (pl. obj.) 'drop' }\end{array}$

Of course, when one is navigating a conversation or text, the difference between a passive prefix $p$ - and a stem-initial $p$ is not obvious. But there are important pieces of evidence that make clear that something has happened. These are presented below. Sections 2.1-2.5 present evidence for the morphological composition of the verbs in question. With one major exception (see 2.5), which I take as a morphological anomaly that should not be surprising, they clearly point to the fact that reanalysis has taken place.

\subsection{Subject Nominalizer Allomorphy}

The first evidence is based on the shape of the subject nominalizer which occurs with these verbs. The subject nominalizer has three suppletive allomorphs which occur productively with verbs, as shown in (7).

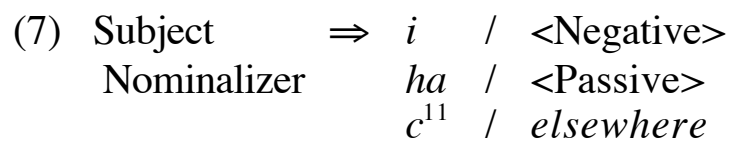

A true passive form takes the allomorph $h a-$ when it is not negative:

(8) ziix ha-p-áhit 'food' (thing SubjNom-Psv-eat, 'thing that is eaten')

The forms in (9) with the allomorph $c$-, however, coexist with the true passives of the original verbs. They do not replace them and do not 'block' the formation of regular passives. Compare (9c) and (10), for example.
(9a) c-paailx SubjNom-go(pl.)
'who go'
(9b) c-paaisx SubjNom-clean
'what is clean'
(9c) c-patj SubjNom-flattened
'what is flattened'
(9d) c-paatjc SubjNom-open
'what is open'

\footnotetext{
${ }^{9}$ An anonymous reviewer has suggested an alternative analysis: a new morpheme has evolved from the passive prefix and this morpheme creates stative verbs, or the passive prefix has generalized into a more general intransitivizer. This analysis has problems, as the one I propose also does, with the disparity between the facts of sections 2.1 and 2.5. Other sections of my presentation are consistent with this alternative. However, there is no good evidence that any kind of productive extension of the passive morpheme has evolved. The relevant verbs, which are few and are all included in this paper, appear to be sporadic idiosyncratic developments. Therefore it seems preferable to me to view this as the reanalysis of the prefixal material into the verb stem.

${ }^{10}$ This verb is used only in certain expressions.

${ }^{11}$ This prefix is orthographically $q u$ - before front vowels, as in Spanish.
} 
(9e) c-ahjiit SubjNom-fall 'what falls'

(10) ha-p-átj SubjNom-Psv-pound.flat 'what was pounded flat' (true passive) ${ }^{12}$

Of the etymological passives, the verb-pacta 'appear' is exceptional in that it continues to use the $h a-$ allomorph, just as the regular passive form does. On other counts, discussed below, this verb - pacta is clearly a reanalyzed passive.

(11) Exceptional: ha-pácta, *c-pacta 'that which appears'

\subsection{Causative Forms}

A true passive form never has a causative prefix in front of it in Seri; one cannot say 'cause to be eaten.' There are no causatives formed on productive passive stems in this language, as illustrated in (12).

$$
\text { *-a-p-áhit (-Aug-Psv-eat, 'cause to be eaten') }
$$

However, the (b) forms such as those in (13-16) may be causativized, so in this characteristic they are like simple intransitives and unlike passives. The causative form in some cases is very similar semantically to the original simple transitive form. Compare:

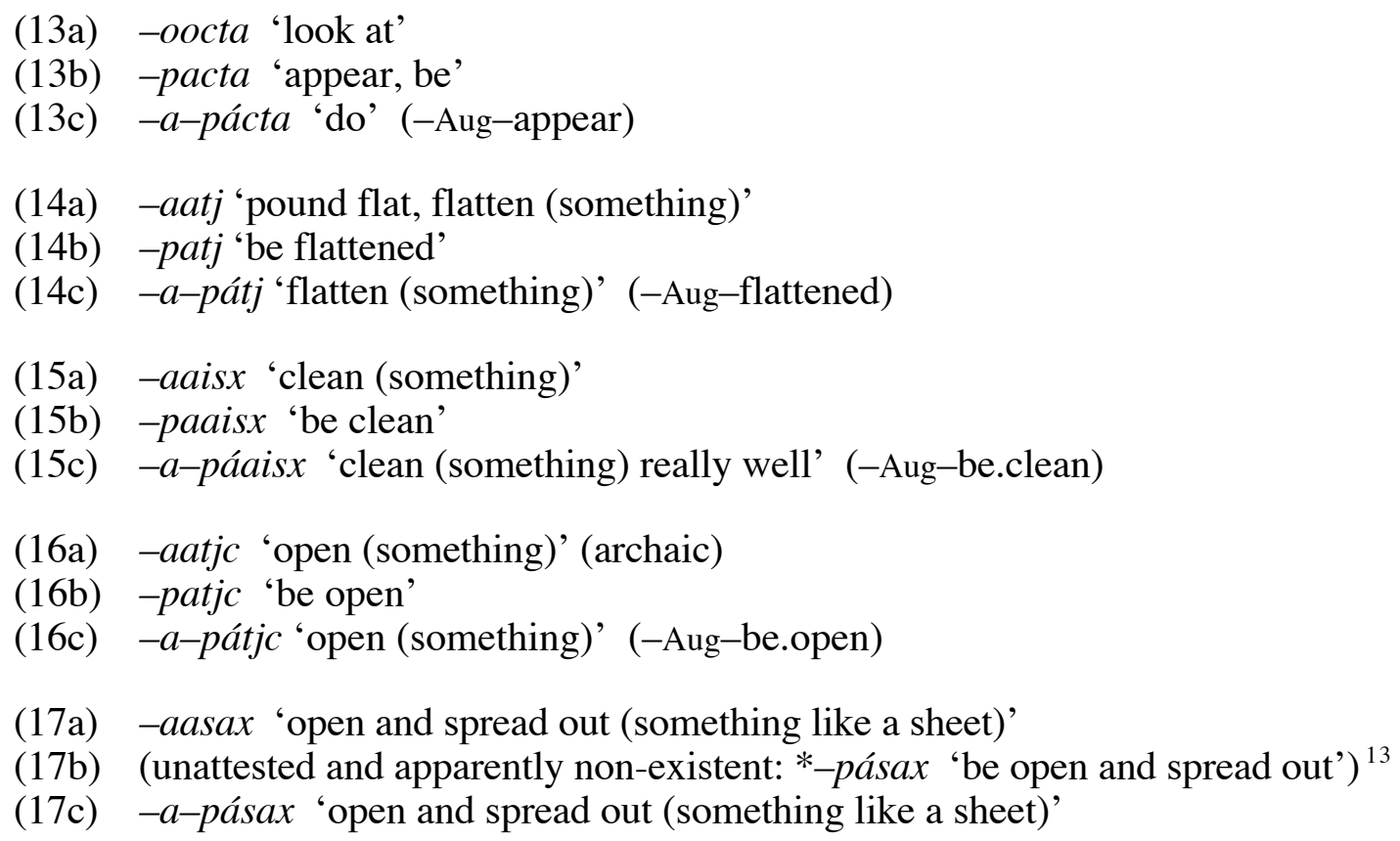

\footnotetext{
${ }^{12}$ This passive verb is homophonous with the passive of the causative verb capátj 'flatten': hapátj 'what was flattened'.

${ }^{13}$ The verb -pasax is not listed as an intransitive verb in the dictionary (Moser et al., in preparation), and the omission is apparently not accidental, from what I have been able to determine.
} 


\subsection{Impersonal Passives}

Another way to distinguish true passives from etymological passives in Seri is based on a language-particular syntactic restriction: except under certain very clear conditions, passives with plural subjects are not permitted. Instead of the sentence we were tattooed (with a first person plural subject), one must say something like it was tattooed $u s$, with an impersonal passive and a first person plural direct object prefix. ${ }^{14}$ This is illustrated in (18).

hizi-y-ah-cázja, 1plDO-Distal-Psv-bite(singular, iterative)

'We were bitten (as by snake).' (More literally, 'It was bitten us.')

(* ha-y-ah-cázjoj, 1plSubj-Distal-Psv-bite(plural))

The verbs with reanalyzed passives may take plural subjects, however: mipáctoj (mi-Ø-páctoj, 2Poss-ActNom-appear/Pl) 'your (pl.) appearing, what you (pl.) are like'; ihahjcóaalam ( $i-h$-ahjcóaalam, 3Poss-ActNom-fall/Pl 'their falling, that they fall'). The underlined word in (19) is the etymological passive related to the verb -aailx 'throw (objects)'. The second line of the following examples is given in underlying form (although it uses the same orthography as the first). The third line glosses the morphemes, while the fourth line glosses the words and idioms.

\begin{tabular}{|c|c|c|c|c|}
\hline Hant iipzx & com & taacoj & toc & cotomma \\
\hline hant $i-\varnothing-a p z x$ & com & $t-a a c o j$ & toc & co-t-oom-ma \\
\hline $\begin{array}{l}\text { land 3Poss-ActNom-tear } \\
\text { gulch }\end{array}$ & $\begin{array}{l}\text { the } \\
\text { the }\end{array}$ & $\begin{array}{l}\text { Rl-big } \\
\text { it.was.large }\end{array}$ & $\begin{array}{l}\text { there } \\
\text { there }\end{array}$ & $\begin{array}{l}\text { 3IO-Realis-lie-DS } \\
\text { it.was }\end{array}$ \\
\hline iqui & $z a a j$ & $\underline{\text { ha-m-páailx. }}$. & & \\
\hline$i-a q u i$ & $z a a j$ & ha-mi-paailx & & \\
\hline $\begin{array}{l}\text { 3Poss-toward } \\
\text { we.arrived.at.the.sea }\end{array}$ & cave & 1plSubj-Proxima & 1-go & \\
\hline
\end{tabular}

\subsection{Switch Reference}

Other evidence that distinguishes true passives from etymological passives in Seri is based on the switch reference system (Moser 1978; Marlett 1981; Marlett 1984; Farrell, Marlett and Perlmutter 1991). The surface subjects of simple intransitive verbs count for the switch reference system, but the surface subjects of passive clauses do not; in the case of the latter, it is the agent that counts. The relevant notion of subject for switch reference in Seri is something other than surface subject. ${ }^{15}$

In this respect, the etymological passives work just like simple intransitives in the examples we have seen: the surface subject is the relevant nominal for the switch reference system. In the following example, the important transition is between the second and third clauses. If the third clause had a true passive verb (rather than an intransitive verb - ahjiit 'fall' that now simply looks

14 It is argued in Marlett (1981, chapter 12) and Marlett (1984) that this prefix here actually cross-references a chômeur (in Relational Grammar terms).

${ }^{15}$ In raising constructions, it is the raised subject that counts. See especially Farrell, Marlett and Perlmutter (1991) for discussion. 
like a passive), the well-established pattern in the language would demand a different subject marker $(\mathrm{ma})$ at the end of the second clause. ${ }^{16}$

\begin{tabular}{|c|c|c|c|}
\hline & Ihptcmitáamt & ipi & 'I was going without shoes,' \\
\hline UF & $h p-t-m-i-t a ́ a m t$ & ipi & \\
\hline & $\begin{array}{l}\text { 1sSubj-Realis-Negative-with-shoes } \\
\text { I.was.without.shoes }\end{array}$ & $\begin{array}{l}\text { even } \\
\text { even }\end{array}$ & \\
\hline
\end{tabular}

$\begin{array}{lllll}\text { hehe án com ano hptiihtim } & \text { 'I was out in the desert,' } \\ \text { UF: hehe an com ano } & \text { hp-t-iihtim } \\ \text { plant } & \text { area } & \text { the } & \text { 3Poss/in } & \text { 1sSubj-Realis-be/Iterative } \\ \text { desert the } & \text { in } & \text { I.was } & \end{array}$

\begin{tabular}{|c|c|c|c|c|}
\hline \multirow{3}{*}{ UF: } & $\cos i$ & ano & hptahjíitma & \multirow{3}{*}{ 'I fell on a thorn,' } \\
\hline & $\operatorname{cosi}$ & ano & $h p-t-a h \overline{j i i t}-m a$ & \\
\hline & $\begin{array}{l}\text { thorn } \\
\text { thorn }\end{array}$ & $\begin{array}{l}\text { 3Poss/on } \\
\text { on }\end{array}$ & $\begin{array}{l}\text { 1sSubj-Realis-fall-DS } \\
\text { I.fell }\end{array}$ & \\
\hline
\end{tabular}

UFo $\begin{aligned} & \text { he tapxölimma } \\ & \text { ano he-t-apxölim-ma }\end{aligned}$
3Poss/in 1 1O--Realis-break-DS
it.broke.off.in.me

$\begin{array}{lll} & \text { hita } & \text { hin yacósejc. }\end{array}$ 'my mother removed it from me.'

\subsection{Action/oblique Nominalizer Allomorphy}

The action/oblique nominalizer displays regular suppletive allomorphy. The allomorph which always occurs before the $a h-$ passive allomorph (namely $h-$ ) is different than that which occurs before low back vowels of superficially intransitive verbs (namely $y-$ ). Compare the following:

(21a) hihacázni 'my being bitten' (<\{hi-h-ah-cazni\},1Poss-ActNom-Psv-bite)

(21b) ihyáafzx 'my sneezing' ( $<\{h i-y-a a f z x\}$, 1Poss-ActNom-sneeze)

(21c) yahái 'its shimmering' (< $\{i-y-a h a ́ i\}$, 3Poss-ActNom-shimmer)

If the verbs in question, (6f-g), are true passives, we expect the allomorph $h-$, but if they are now verbs which are vowel-initial intransitives, we expect the allomorph $y$-. For these two verbs, however, the results are not what are expected under a reanalysis hypothesis. The (passive-related)

\footnotetext{
${ }^{16}$ Simplifying things for the present purposes, we may say that 'different subject' is marked at the end of a finite subordinate clause if the following clause has a different 'logical' subject (even if that logical subject is the unexpressed agent of a passive verb). The 'logical' subject of the second clause is 'I'; the 'logical' subject of the third clause if it were a passive would be some Unspecified person; this situation would require a different subject marker on the end of the second clause.
} 
$h$ - allomorph of the action/oblique nominalizer prefix occurs with the two verbs which are putatively $a$-initial (see 6 f-g).

hant c-ahjiit 'who falls'
down SubjNom-fall

Exceptional:

hant $m i-h-a j i$ it 'your falling' c-ahcáil'what remains, what is lacking'

SubjNom-remain

Exceptional:

$m i-h-a c a ́ i l$ 'your remaining' ('that you remain')

)$(<\{m i-h-a h c a ́ i l\}, 2$ Poss-ActNom-fall $)$

Thus the morphology is somewhat irregular for these verbs on the assumption that they are not synchronically passive; the morphology for the action nominalizer with these verbs is just what is expected of synchronic passives. If one were to assume that they are synchronically passive, however, they are irregular in the subject nominalized form, as already seen in section 2.1.

\subsection{Conclusion}

In the preceding sections I have presented four arguments that support the claim that a few passive verbs in Seri have been lexicalized as intransitive verbs without the loss of the productive passive form. Two arguments are morphologically-based and two are syntactically-based. Especially in one area of the morphology (the action/oblique nominalizer, discussed in section 2.5), the facts do not support the claim of reanalysis. It seems significant, however, that these are morphological oddities (a total of three word-forms) and not syntactic oddities.

\section{Etymological Negatives}

The negative morpheme in Seri is the prefix $m-$. The $m$ which appears in the forms in (23) is derived from this prefix, as comparison with the verbs stems on the right makes obvious. Like with the passive prefixes, however, the two are not immediately distinguishable.

(23a) -miha 'go slow'

(23b) -miih 'scarce'

(23c) hacx-miih 'die'

(24d) haai-mipi 'difficult'

(24e) -moquépe 'sick'

(24f) -maco 'hidden, hard to see'

(24g) haa-maco 'difficult' cf. -iha 'go fast'

$c f .-i i h$ 'be (located)'

cf. haai-ipi 'easy' 17

cf.-oquépe 'comfortable'

$c f$. -aco 'visible, obvious'

In the following sections I provide tests for the morphological composition of these verbs. The evidence is clear that reanalysis has taken place.

\footnotetext{
${ }^{17}$ The syntax of these expressions ('easy' and 'difficult') is apparently not parallel. The two expressions may have become more divergent than one might have expected.
} 


\subsection{Subject Nominalizer}

One simple way to distinguish productive negatives from etymological negatives is with the subject nominalizer discussed in section 2.1 above. Recall that this prefix has the allomorph $i-$ in negative forms, and $c-/ q u-$ in non-passive non-negative forms.

(24a) $i-m-p-a$ hit SubjNom-Neg-Psv-eat, 'what is not eaten'

(24b) $i-m-a ́ h i t \quad$ SubjNom-Neg-eat, 'who does not eat it'

(24c) $q u-i-h i t \quad$ SubjNom-OM-eat, 'who eats it' (25).

All of the verbs listed in (23) take the allomorph $c$ - for the subject nominalizer, as shown in

(25a) c-miha SubjNom-go.slow 'what goes slow'

(25b) hacx c-miih somewhere SubjNom-not.be 'who dies'

(25c) c-moquépe SubjNom-sick 'who is sick'

(25d) c-miih SubjNom-not.be 'what is scarce'

(25e) haai c-mipi ? SubjNom-? ${ }^{18}$ 'what is difficult'

(25f) c-maco SubjNom-hidden 'what is hidden'

Because the reanalysis of some $m$ 's as stem consonants does not affect the productivity of the original verb stems and negative affix, (26a) coexists in the language with (25a), (26b) with (25b), etc.

$\begin{array}{lll}\text { (26a) } i-m-i h a & \text { SubjNom-Neg-fast } & \text { 'what is not fast' } \\ \text { (26b) hacx i-m-iih } & \text { somewhere SubjNom-Neg-be } & \text { 'who isn't somewhere' } \\ \text { (26c) } i-m-\text { oquépe } & \text { SubjNom-Neg-comfortable } & \text { 'who is not comfortable' } \\ \text { (26d) } i-m-i i h & \text { SubjNom-Neg-be } & \text { 'what isn't' } \\ \text { (26e) haai } i-m-i p i & \text { ? SubjNom-Neg-? } & \text { 'what isn't easy' } \\ \text { (26f) } i-m-\text { aco } & \text { SubjNom-Neg-visible } & \text { 'what isn't visible / obvious' }\end{array}$

\subsection{Causative Forms}

A second piece of evidence for the reanalysis is based on the formation of causatives. In regular verbs, the negative (inflectional) cannot occur 'inside' of the causative morpheme (derivational); there is no productive way to make a morphological causative meaning 'cause to not $\mathrm{X}$ ', as shown in (27).

$$
\text { *-a-m-áhit 'cause to not eat' }
$$

But in etymological negatives, the causative prefix may occur on the verb before the $m$.

(28a) -a-míhat 'do slowly' (based on the verb -miha 'slow')

(28b) hacx-a-míihit 'kill' (based on the verb hacx-miih 'die')

\footnotetext{
${ }^{18}$ The parts glossed with a question mark do not have meanings independent of the idioms in which they appear.
} 


\section{3. 'Double' Negative}

A third piece of evidence for the reanalysis looks at the possibility of negation. In regular verbs, only one instance of negation per verb is allowed; there is no way to form a double negative morphologically. Etymological negatives may be negated, however, so the verbs may have two $m$ 's, as shown in (29).

(29a) hacx tommíih 's/he didn't die' (UF: hacx $t-m-m i i h$, somewhere Realis-Neg-not.be)

(29b) immácoha 'it isn't hard to see' (UF: i-m-maco-ha, SubjNom-Neg-hidden-Decl)

(29c) haa xommáco 'it isn't difficult' (UF: xo-m-maco, Emphatic-Neg-hidden)

(29d) haai xommípi 'it isn't difficult' (UF: haai xo-m-mípi, ? Emphatic-Neg-?)

\subsection{Negation of Proximal $m i-$ and Infinitive}

Two more pieces of evidence are based on unexplained morphological gaps in verb formation. In regular verbs, the (inflectional) proximal realis prefix $m i-$ (with rule-derived allomorph impreconsonantally) and the infinitive prefixes (ica- for intransitives, iha- for transitives) cannot cooccur with the negative prefix. As illustrated with the verb -atax 'go' in (30), a verb may be inflected for Proximal Realis, Distal Realis, Neutral Realis, Emphatic Realis, Dependent Irrealis, Independent Irrealis, Imperative, Infinitive, and other things. However, no verb may be inflected for the negative of the Proximal Realis or the negative of the Infinitive. (The finite verbs in (30) are third person singular forms.)

\begin{tabular}{|c|c|c|}
\hline 'go' -atax & Affirmative & Negative \\
\hline Distal Realis yo- & yootax & yomátax \\
\hline Neutral Realis $t-$ & tatax & tmatax \\
\hline Emphatic Realis $x o-$ & xootax & xomátax \\
\hline Dependent Irrealis po- & pootax & pomátax \\
\hline Independent Irrealis $s i-$ & siitax & smatax \\
\hline Imperative $^{19} c-$ & catax & cmatax \\
\hline Proximal Realis $m i-$ & miitax & (no form possible; expected immátax) \\
\hline Infinitive & icátax & (no form possible; expected icamátax) \\
\hline
\end{tabular}

However, the Proximal prefix $m i-$ does co-oocur with all of the etymological negatives; a few examples are shown below.

(31a) hacx immíh 's/he died' (UF: mi-miih, Proximal-die)

(31b) immáco 'it is hard to see' (UF: mi-maco, Proximal-hidden)

(31c) immíha 'it goes slow' (UF: mi-miha, Proximal-slow)

(31d) immoquépe 's/he is sick' (UF: mi-moquépe, Proximal-sick)

The etymological negatives also have infinitival forms, as shown in (32).

(32a) hacx icamiih 'to die' (UF: hacx ica-miih, somewhere Infinitive-not.be)

(32b) icamoquépe 'to be sick' (UF: ica-moquépe, Infinitive-sick)

\footnotetext{
${ }^{19}$ The imperative morpheme has this shape before short low root-initial vowels and whenever a verb is negative.
} 


\subsection{Prefix Order}

The order of morphemes in Seri verbs stipulates that the 'unspecified subject' prefix follows the negative prefix. However, the negative part of the etymological negative occurs after the unspecified subject prefix, exactly as expected if it were now part of the stem. Both of these facts are illustrated by example (33). Note that the prefix $c a$ - is sandwiched between $m$ 's. The one on the left is the productive negative inflection; the one on the right is the reanalyzed negative which is now part of the verb stem. (The $o$ is epenthetic.)

(33) hacx somcamíihaha 'One will not die.'

UF: $\quad s i-m-c a-m i i h ~ h a-h a$, Irrealis-Neg-UnspSubj-die Auxiliary-Decl)

\section{6. k-Epenthesis}

A sixth way to distinguish true negatives from etymological negatives is based on a somewhat bizarre, but fully productive, phonological rule which inserts a velar stop in the (admittedly curious) context shown below:

$$
\varnothing \rightarrow \mathrm{k} /[+ \text { segment }][+ \text { coronal }] \_[+ \text {nasal }]+
$$

This is illustrated by the following data, where the (compressed) derivation is still given in practical orthography:

$\begin{array}{lll} & \text { 's/he didn't do it' } & \text { 'you didn't fly' } \\ & \text { OM-Realis-Neg-do } & \text { 2sSubj-Realis-Neg-fly } \\ \text { Underlying } & i-t-m-a a i & \text { m-t-m-cap } \\ \text { k-Insertion } & \text { itcmaai } & \text { mtcmcap } \\ \text { Other rules } & \text { itcmaai } & \text { intcomcap } \\ \text { Surface } & \text { itcmáai } & \text { intcomcáp }\end{array}$

Crucial to the application of this rule is the fact that the nasal consonant is not a stem consonant; a morpheme boundary must follow the nasal consonant if $\mathrm{k}$-epenthesis is going to apply. Underlying $\{i-t-m i s\}$ (OM-Realis-resemble) has the surface form itmís 's/he resembled him/her/it'; $\mathrm{k}$-epenthesis does not apply in such cases.

As shown in (36), the verbs in question do not pattern with true negatives; k-Epenthesis does not apply. These facts provide clear evidence that no morpheme boundary follows the $m$ in these verbs.

\footnotetext{
ihptmoquépe 'when I was sick',1

$\mathrm{UF}: h p-t-$ moquépe

1sSubj-Realis-sick
}

\footnotetext{
${ }^{20}$ All cases of k-Epenthesis are with the negative morpheme.

${ }_{21}$ The word ihptcmoquépe ( $<\{h p-t-m$-oquépe $\}$ (1sSubj-Realis-Neg-comfortable), with k-Epenthesis having applied, is 'when I was not comfortable'.
} 


$$
\begin{array}{ll} 
& \text { ihptmíha 'when I was going slowly' } \\
\mathrm{UF}: & h p-t-m i h a \\
& \text { 1sSubj-Realis-slow }
\end{array}
$$

\subsection{Other Potential Tests and Conclusion}

Two more tests are potentially available. First, the object nominalizer has a different form before the negative morpheme than before simple consonants. However, all of the verbs with reanalyzed negatives that I have found are intransitive verbs and so this test cannot be put to use at present. Second, negative morphology cannot occur inside of passive morphology (that is, closer to the root) in regular verbs. The prediction is that passives of etymological negative verbs should be possible. Again, since all of the verbs with reanalyzed negatives are intransitive verbs, this test cannot be used yet. ${ }^{22}$

Seven arguments have been presented in support of the hypothesis that five verbs of Seri are best analyzed as etymological negatives. Six of these are based on morphology, and one is based on a phonological rule which is sensitive to the presence of a morpheme boundary in precisely the relevant position. As with the passive cases already considered, this reanalysis has not affected the productivity of the negative prefix generally.

\section{Is Reanalysis Gradual or Not? How and Why Does It Happen?}

Despite clear morphological and syntactic evidence that distinguishes passives from $p$-initial stems, and despite morphological and phonological evidence that distinguishes negatives from $m$-initial stems, a structural change in the analysis of certain verbal forms is taking place, or has taken place. This seems to be well established. The process is one of reanalysis, resulting in new lexical items while at the same time leaving the productivity of the original morphemes intact. Haspelmath (1992, 1998) distinguishes reanalysis from grammaticalization. He argues that the latter is a gradual process, and that reanalysis is not gradual (although in the case of the latter the change may spread gradually through the speech community and although any speaker may have two representations, before and after reanalysis). One fact that might be used to argue that the Seri case is gradual, pace Haspelmath, is the suppletive allomorphy which now irregularly reflects the previous analysis in the case of verb forms such as hapácta (11) and mihajiit (22). However, this is not truly convincing; if the process were truly gradual, one should expect to find a more convincing array of irregularity, including with the syntactic facts (e.g., the switch reference facts discussed in section 2.4).

It is not clear what is driving the reanalysis. In these particular cases in Seri, reanalysis is not motivated by any instability in the morphology, nor by any phonological change, nor by the lack of productivity of the affixes; there is no leveling of irregularity. Most passive and negative forms in the language are ambiguous with respect to reanalysis; the only facts (to my knowledge) which indicate that reanalysis has taken place are those discussed in the preceding sections. Consider the verbs -iha 'fast' and -miha 'slow'. While I have shown that the subject nominalized form for the negative of -iha 'fast' is different than the subject nominalized form for the verb -miha 'slow', it

\footnotetext{
${ }^{22}$ All of the verbs formed by reanalysis in Seri are intransitive. With reanalysis of the passive, this is simple: passives are intransitive. With the reanalysis of the negative, this fact is more interesting. It would be more difficult to envision the lexicalization of a transitive 'not eat it' than intransitive 'not eat' ('fast (abstain from eating)'), 'not slow' ('fast, quick') or 'not visible, not clear' ('invisible, obscure'), even though the base predicates are morphologically verbs in Seri in all these cases. Nevertheless, this may be an accidental fact since one might expect to find a lexicalized verb meaning 'forget' in the future based on the negative of the verb 'remember'.
} 
remains true that most verb forms with the string miha could belong to either paradigm, as illustrated in (37).

$\begin{array}{lll} & \text { Negative of -iha 'fast' } & - \text { miha 'slow' } \\ \text { yomíha } & \text { 'it was not going fast' } & \text { or 'it was going slow' } \\ \text { pomíha } & \text { 'if it is not going fast...' } & \text { or 'if it is going slow...' } \\ \text { xomíha } & \text { 'it wasn't going fast!' } & \text { or 'it wasn't going slow!' } \\ \text { smihaha } & \text { 'it will not be going fast' } & \text { or 'it will be going slow', } \\ \text { tmiha } & \text { 'it wasn't going fast...' } & \text { or 'it was going slow...' } \\ \text { imíha } & \text { 'the fact of its not going fast' } & \text { or 'the fact of its going slow' }\end{array}$

This means that in many cases the speaker and hearer are not forced to make a decision about which verb is involved.

We might consider the kind of verbs that are being created. In the case of the negatives, a number of new verbs are being created that are antonyms - semantic opposites, or contrary (as opposed to contradictory) forms (Horn 1978:131-2, Horn 1989). Thus we have -miha 'slow' from -iha 'fast'; haai -mipi 'difficult' from haai -ipi 'easy'; and -maco 'hidden, hard to see' from - aco 'visible, obvious'. (Three new verbs are not quite so closely related semantically to the verbs to which they are related etymologically: - miih 'scarce' and hacx - miih 'die', from -iih 'be (located)', and -moquépe 'sick', from -oquépe 'comfortable'.) There are no other lexical expressions for 'slow', 'hidden, invisible', 'sick (general sense)' in the language. The expression hacx - miih 'die' is used for people, and perhaps developed as a euphemism, since it contrasts quite sharply with a verb -oxi that is now used primarily for animals. (The verb -oxi has the flavor of 'croak' when applied to people.) Is it possible that part of the motivation for the reanalysis is some kind of perceived 'gap' in the lexicon? The language actually has a number of similar gaps. The following verbs are a few of those that do not have any lexicalized antonyms: -iipe 'good' (no verb for 'bad'), -ahtxima 'rich' (none for 'poor'), -Camjö and -inéhj 'shiny' (none for 'dull'), -azíim ${ }^{23}$ 'pretty' (none for 'ugly'), -mozime 'drunk' (none for 'sober'), -atol 'wild' (none for 'tame'), -acösxaj 'long' (none for 'short'), -yail 'deep' (none for 'shallow'), to name a few. The opposites of these are expressed by simple negation of the verb. At this point, all I can do is speculate that this 'gap in the lexicon' may be a small factor.

\section{Conclusion}

Seri data have been presented which illustrate one kind of reanalysis - the loss of a morpheme boundary - in a clear way. Phonological, morphological, and syntactic evidence demonstrates that in a handful of cases the negative prefix and the passive prefix have been reinterpreted as part of the verb stem rather than as prefixes. Such a reanalysis, resulting in the lexicalization of forms without the loss in any way of the productivity of the original forms, seems straightforward, although analogous cases are not presented in the literature, to my knowledge. What we do not know at this time, however, is what has motivated this reanalysis and how it is taking place.

\footnotetext{
${ }^{23}$ This verb is derived from the root for 'enjoy', -zim.
} 


\section{References}

Andersen, Henning. 1973. Abductive and deductive change. Language 49:765-93.

Farrell, Patrick, Stephen A. Marlett \& David M. Perlmutter. 1991. Notions of subjecthood and switch reference: Evidence from Seri. Linguistic Inquiry 22:431-56.

Haspelmath, Martin. 1992. Grammaticization theory and heads in morphology. Morphology now, ed. by Mark Aronoff, 69-82. Albany: SUNY Press.

Haspelmath, Martin. 1998. Does grammaticalization need reanalysis? Studies in Language 22/2: 325-51.

Hoenigswald, Henry M. 1960. Language change and linguistic reconstruction. Chicago: University of Chicago Press.

Hopper, Paul J. \& Elizabeth Closs Traugott. 1993. Grammaticalization. Cambridge: Cambridge University Press.

Horn, Laurence R. 1978. Some aspects of negation. Universals of human language, vol. 4 Syntax, ed. by Joseph P. Greenberg,127-210. Stanford: Stanford University Press.

Horn, Laurence R. 1989. A natural history of negation. Chicago: University of Chicago.

Langacker Ronald W. 1977. Syntactic reanalysis. Mechanisms of syntactic change, ed. by Charles N. Li, 57-139. Austin: University of Texas Press.

Marlett, Stephen A. 1981. The structure of Seri. Dissertation, University of California at San Diego.

- - - . 1984. Impersonal passives in Seri. Studies in Relational Grammar 2 ed. by Carol Rosen and David M. Perlmutter, 217-39. Chicago: University of Chicago Press.

- - . 1990. Person and number inflection in Seri. International Journal of American Linguistics 56:503-41.

Moser, Mary B. 1978. Switch reference in Seri. International Journal of American Linguistics 44:113-20.

Moser, Mary B. et al. In preparation. Seri dictionary (Seri-Spanish-English).

Stemberger, Joseph P. \& Stephen A. Marlett. 1983. Empty consonants in Seri. Linguistic Inquiry 14:617-39.

Author's contact information:

Stephen Marlett

PO Box 8987

Catalina, AZ 85738-0987

steve_marlett@sil.org 